\title{
Comparative Evaluation of Quality of Obturation and Its Effect on Postoperative Pain between Pediatric Hand and Rotary Files: A Double-blinded Randomized Controlled Trial
}

\author{
Ganesh Jeevanandan ${ }^{1}$, Lavanya Govindaraju², Erulappan Muthu Ganapathi Subramanian ${ }^{3}$, Pragyna Priyadarshini ${ }^{4}$
}

\begin{abstract}
Background: One of the cardinal points to be considered during endodontic procedures in children is the measure of postoperative pain. Aim and objective: To evaluate the quality of obturation and its effect on postoperative pain with three file systems in primary mandibular molars during 1 week follow-up.

Materials and methods: The study was conducted as a double-blinded randomized controlled trial. The participants between 6 years and 9 years old requiring a pulpectomy were recruited for the trial. Forty-five primary mandibular molars were randomly allocated into 15 teeth each in Hand K-files; Kedo-SH and Kedo-SG Blue groups. Wong Baker's FACES Pain Rating Scale was used for assessing the postoperative pain in the children for 1 week. Pearson's Chi-square test, Kruskal-Wallis test, and Mann-Whitney $U$ test were used for analyzing the data statistically. Results: Optimal fillings were observed more in the Kedo-SG Blue group (80.0\%) compared to the other two groups $(p<0.017)$. On intergroup analysis, the Kedo-SG Blue group reported less postoperative pain compared to Kedo-SH group on day 1 while on day 7 no postoperative pain was experienced in either of the groups. Less postoperative pain was reported by the children in whom the canals were optimally filled compared to overfilling and underfilling.

Conclusion: Kedo-SG Blue resulted in less postoperative pain when compared to Kedo-SH and hand K-files, whereas optimally filled children experienced less postoperative pain compared to overfilling and underfilling.

Clinical significance: A felicitous pediatric dental practice includes appropriate assessment and management of postoperative pain in children. Hence, the present study is important in highlighting the affiliation of postoperative pain with quality of obturation following an endodontic intervention in children.
\end{abstract}

Keywords: Postoperative pain, Primary molars, Pulpectomy, Quality of obturation, Randomized controlled trial.

International Journal of Clinical Pediatric Dentistry (2021): 10.5005/jp-journals-10005-1895

\section{INTRODUCTION}

Endodontic interventions are the most sought-after procedures performed on the diagnosis of pulpal inflammation and pathosis; however, in primary teeth, endodontic treatment poses substantial difficulties owing to its complex anatomy and canal systems. ${ }^{1}$ Maintaining successful root canal treated primary teeth has the advantage of preserving the natural tooth which is considered as the best possible space maintainer. ${ }^{2,3}$ In cases of irreversible pulpitis, endodontic therapy remains the most common and frequently performed procedure to alleviate pain. ${ }^{4,5}$ The primary goal of instrumentation in pulpectomy of primary teeth is the effective removal of organic debris, ${ }^{6,7}$ however, in primary teeth, biomechanical preparation is more chemomechanical in nature where effective instrumentation coupled with adequate irrigation serves the purpose. During chemomechanical preparation of the root canals, any instrumentation technique can cause apical extrusion of debris ${ }^{8-11}$ such as dentinal debris, necrotic debris, microbes, pulp tissue remnants, and irrigating solutions which irritates the periradicular tissues, thereby provoking postoperative pain. ${ }^{12,13}$

Pain is an unpleasant multidimensional experience that comprises strong sensory and cognitive components. ${ }^{14}$ The prevalence of postoperative pain in children was found to be $65.6 \%$ after dental procedures whereas its prevalence after endodontic treatment in the general population varies from 3 to $58 \%{ }^{15,16}$ Certain preoperative and postoperative factors are accountable
${ }^{1-4}$ Department of Paediatric and Preventive Dentistry, Saveetha Dental College and Hospitals, Saveetha Institute of Medical and Technical Sciences, Chennai, Tamil Nadu, India

Corresponding Author: Ganesh Jeevanandan, Department of Paediatric and Preventive Dentistry, Saveetha Dental College and Hospitals, Saveetha Institute of Medical and Technical Sciences, Chennai, Tamil Nadu, India, Phone: +91 9884293869, e-mail: helloganz@gmail.com

How to cite this article: Jeevanandan G, Govindaraju L, Subramanian EMG, et al. Comparative Evaluation of Quality of Obturation and Its Effect on Postoperative Pain between Pediatric Hand and Rotary Files: A Double-blinded Randomized Controlled Trial. Int J Clin Pediatr Dent 2021;14(1):88-96.

Source of support: Nil

Conflict of interest: None

for pain after endodontic treatment. Patients experiencing severe preoperative pain are found to be more prone to suffering from moderate to severe postendodontic pain when compared to those without pain before endodontic intervention. ${ }^{17-19}$ Mechanical factors such as root canal instrumentation techniques, ${ }^{20-22}$ over-instrumentation or extrusion of obturating materials ${ }^{23}$ are associated with postoperative pain. Other factors like age, gender, tooth type, pulp status, presence of sinus tracts, and sensitivity with 
existing preoperative pain are also considered to be risk factors that may affect postoperative pain. ${ }^{24}$

Several investigations claim the ability of rotary techniques to minimize extrusion of debris compared to other techniques. ${ }^{24}$ Rotary instruments result in extrusion of less debris compared to stainless steel hand files due to their rotational movements (Archimedes screw effect) leading to less postoperative pain and discomfort when coupled with copious irrigation. ${ }^{24,25}$ No significant difference in the postoperative pain was found in a study comparing manual and rotary instrumentation in permanent mandibular molars with asymptomatic irreversible pulpitis at any intervals. ${ }^{26}$ Another study compared the incidence of postoperative pain during single visit RCT in young permanent teeth on using manual and rotary techniques for canal preparation and reported no statistically significant difference. ${ }^{27}$ In the above clinical trials, assessment of the postoperative pain was based on instrumentation techniques and files designed for permanent teeth. However, only a few investigations on postoperative pain in pediatric dentistry have been so far published. ${ }^{28-30}$

A new dawn on the horizon of pediatric endodontics is the introduction of the manual as well as rotary file system exclusively designed for children. A revolutionary landmark in this field is the evolution of the advanced Kedo-SG Blue rotary and Kedo-SH hand files (Kedo Dental Pvt Ltd., India) for use in children. Rotary instrumentation in primary teeth provides an easier, uniform, and predictable obturation; however, its influence on the occurrence of postoperative pain has been very insignificantly studied. A study by Topçuoğlu et al. reported less incidence of postoperative pain on using the Revo-S rotary system in primary teeth. ${ }^{28}$ Lesser postoperative pain was also reported on using MTwo and Kedo-S rotary systems in primary molars. ${ }^{29}$ A significantly decreased postoperative pain was reported with pediatric rotary Kedo-S files at 6 and 12 hours interval on comparison with $\mathrm{K}$ and $\mathrm{H}$ files in primary teeth. ${ }^{30}$ In all of the above clinical trials, no association between the obturation quality and postoperative pain was established using rotary vs manual instrumentation. There has been no clinical investigation in the existing literature to date which comparatively assesses the association between obturation quality and postoperative pain following the use of advanced pediatric rotary files.

Hence, the rationale behind conducting the present study is to find the association between the quality of obturation and postoperative pain following the use of hand K-files, Kedo-SH, and rotary Kedo-SG Blue file system in pulpally involved primary mandibular molars during 1-week follow-up.

The null hypothesis for the present study states that there is no association between the quality of obturation and postoperative pain in primary molars.

\section{Materials and Methods}

\section{Study Design and Ethical Approval}

The double-blinded randomized controlled clinical trial was conducted in a dental institute for a period of 4 months (September 2018-December 2018). The trial design was approved by the Institutional Scientific Review Board (SRB/MDS/PEDO/18-19/0020) and Ethical Committee (SDC/MDS/18-19/0143) in accordance with the ethical standards laid down in the 1964 declaration of Helsinki and its later amendments. The parents or caretakers signed the written informed consent of the recruited participants before the beginning of the trial. Each stage of the present study was designed and conducted according to the CONSORT guidelines for a randomized controlled trial ${ }^{31}$ (Flowchart 1).

\section{Sample Size}

Forty-five children (6-9 years) with any one of the primary mandibular molars requiring pulpectomy and with the chief complaint of pain were selected for the trial. Before commencement of the main trial, a pilot study with 15 participants was conducted ( 5 per group) and 45 was the sample size estimated for the main study (15 participants per group) with an allocation ratio of 1:1:1 at $95 \%$ power.

Healthy children with any one of the primary mandibular molars requiring pulpectomy were selected. Also, other factors that were taken into inclusion and exclusion criteria were the root length, coronal structure available, resorption, special children, and systemic diseases. A computerized randomization sequence was generated. Children qualifying the inclusion criteria were enrolled into the trial and were randomly allocated based on the sequence generated. Group I (control group-15 teeth)-hand K-files were used, group II (experimental group, $n=15$ ) Kedo-SH hand files were used, and in group III (experimental group, $n=15$ ) rotary Kedo-SG Blue file system was used.

\section{Study Tool}

Wong Baker's FACES Pain Rating Scale (WB-FPRS) was employed to assess both the pre- and postoperative pain levels in children following the use of hand-K files, Kedo-SH files, and Kedo-SG Blue rotary file system for pulpectomy. The scale is a pictorial representation of the discomfort level experienced by children which comprise six faces, each depicting an expression of pain. The first face in the pictorial scale represents an expression of "no hurt" $(0)$, the second face represents "hurt little bit" (2), the third face represents "hurt little more" (4), the fourth face represents "hurts even more" (6), the fifth face represents "hurts whole lot" (8), and the sixth/last face represents "hurts worst" (10). Scoring of pain severity is outlined as (0): "no pain", (1-3): "mild pain", (4-6): "moderate pain", and (7-9): "severe pain". Based on the scoring of pain severity WB-FPRS: face "no hurt" corresponds to "no pain", face "hurt little bit" corresponds to "mild pain", face "hurt little more" and "hurts even more" corresponds to "moderate pain", face "hurts whole lot" and "hurts worst" corresponds to "severe level of pain". 32 Each of the facial representations in the pictorial scale is assigned with a score (i.e., $0,2,4,6,8,10)^{33}$ (Fig. 1).

Each recruited participant was thoroughly explained and made to understand each of the pictorial facial expressions depicting a certain level of perception of pain in the WB-FPRS. Children were then asked to subjectively rate their existing pain perception into one of either six representations of facial expression for pain. For assessing the postoperative pain level over telephonic conversation, each participant was provided with a printed sheet of WB-FPRS to indicate their postoperative pain level. Postoperative pain assessment was noted over a period of 7 days ( 1 week) including the day of completion of the procedure. Data pertaining to the pre- and postoperative pain assessment was obtained by another author of the study who was blinded to the intervention groups.

\section{Clinical Procedure}

A single trained pediatric dentist performed all the pulpectomy procedures. Each of the recruited participants was blinded to the intervention group. Preoperative pain assessment was noted subjectively using the WB-FPRS. $2 \%$ lignocaine with 1:200,000 
Flowchart 1: Study design according to CONSORT guidelines

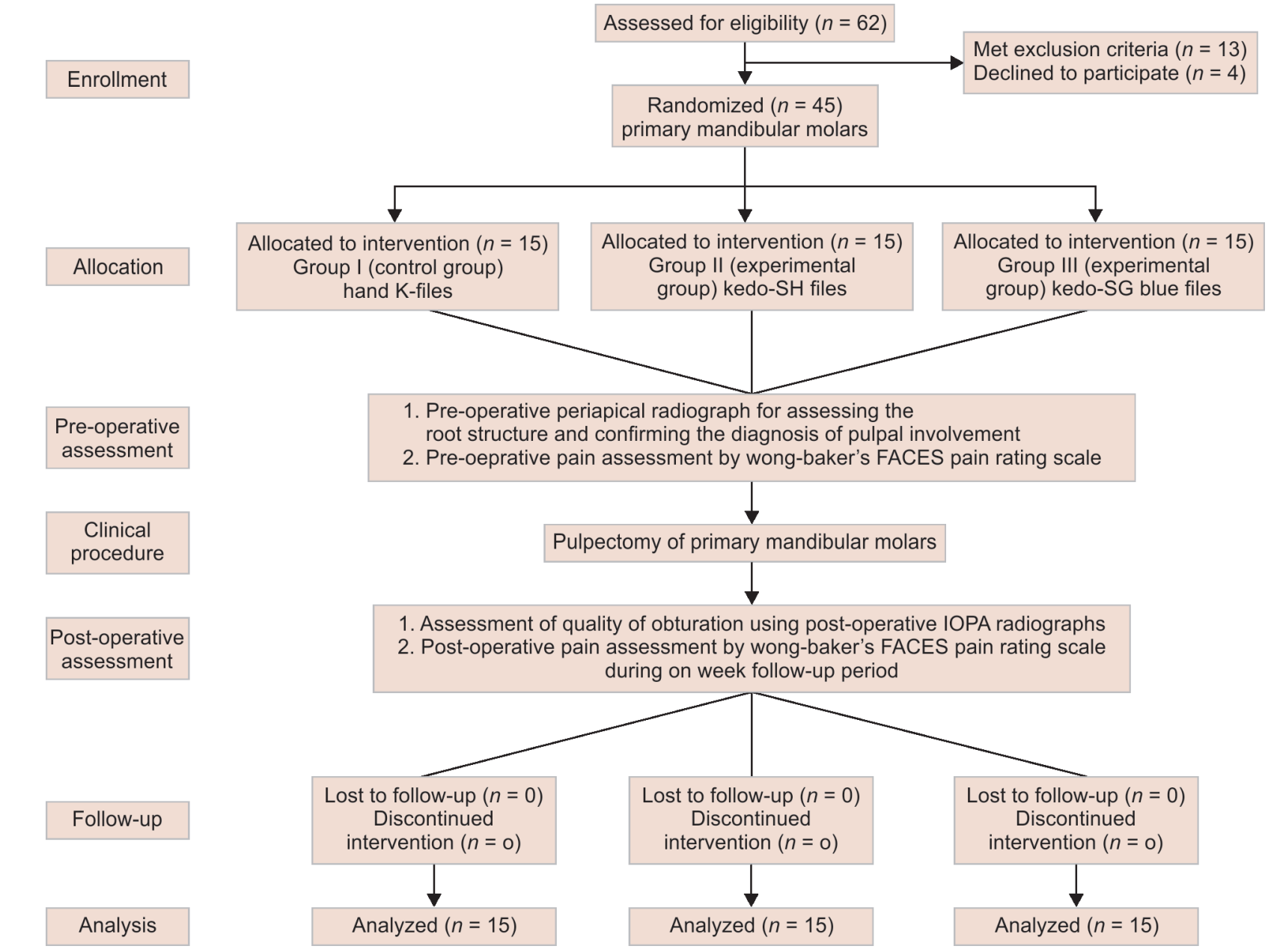

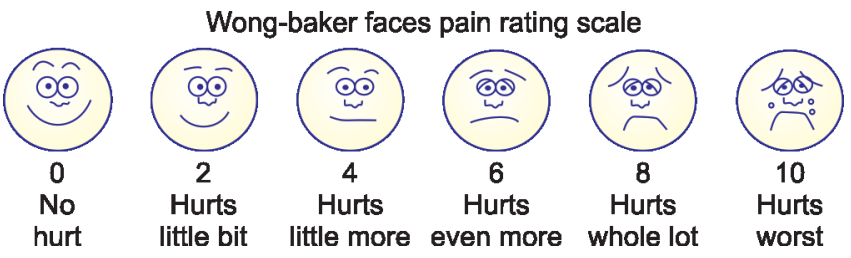

Fig. 1: Wong-Baker faces pain rating scale used in the present study

adrenaline (LOX* 2\% ADRENALINE, Neon Laboratories limited, India) was administered to the tooth indicated for pulpectomy. A rubber dam (GDC Marketing, India) was used to isolate the teeth. The superficial caries was removed using No. 330 pear-shaped carbide bur (Mani, Inc., Tochigi, Japan). A spoon excavator (Hu-Friedy Mfg. Co. LLC) was used to remove the coronal pulp. Patency of the canals was determined using No. 10 size K-file (Dentsply Maillefer, OK, USA). ProPex Pixi electronic apex locator (Dentsply Maillefer, OK, USA) was used to determine the working length.

Group I ( $N=15 /$ control group): Hand K-files (Dentsply Maillefer, OK, USA) from No. 15 size till 35 size was used in the quarter-pull turn method.

In group II ( $N=15$ /experimental group): Kedo-SH hand files (Kedo Dental Care Pvt. Ltd. India) was used sequentially. The patency of the canals was achieved with a $2 \%$ taper No. 15 size (white color-coded) stainless steel file. Extirpation of the pulpal tissue was accomplished with a $2 \%$ taper No. 20 size (yellow) stainless steel Kedo-SH file. No. 25 and No. $30 \mathrm{Ni}-\mathrm{Ti} \mathrm{D}_{1}$ (red color-coded with tip diameter 0.25 ) and $\mathrm{E}_{1}$ (blue color-coded with tip diameter 0.30 ) files with variably variable (VV) taper were used for cleaning and shaping of the canals. In group III ( $N=15$ /experimental group): the root canals were instrumented using a rotary Kedo-SG Blue file system (Kedo Dental Care Pvt. Ltd. India) as per the manufacturer's recommendation. The rotary files were used with an X-Smart endodontic motor (Dentsply Maillefer, OK, USA) at $300 \mathrm{rpm}$ and $2.4 \mathrm{~N} / \mathrm{cm}$ torque till the entire working length in a lateral brushing motion for a minimum of 1-2 times in each canal of the tooth.

$1 \%$ sodium hypochlorite (SEPTODONT, HEALTHCARE, Pvt. Ltd) and normal saline (Fresenius Kabi India, Pvt. Ltd) were used for irrigation of the canals. The files were coated with 17\% EDTA gel (RC Help, Prime dental products, Pvt. Ltd. India) during instrumentation. Sterile paper points were used to dry the canals and were obturated with Metapex (Meta Biomed Co. Ltd, Chungbuk, Korea). An immediate postoperative intraoral periapical radiograph was obtained for assessment of the obturation quality. A preformed stainless steel metallic crown (3M ESPE) was placed after 7 days.

\section{Assessment of Quality of Obturation}

Coll and Sadrian criteria ${ }^{34}$ were used for assessment of the quality of obturation. The assessment was done by two blinded pediatric dentists. A moderate level of agreement (Cronbach's alpha value of 0.76 ) was found between the examiners. 
Table 1: Demographic variables depicting sample size, age, gender, tooth type distribution, and preoperative cause of pain in each group with overall $p$ value

\begin{tabular}{|c|c|c|c|c|c|}
\hline Treatment groups & $\begin{array}{l}\text { Hand-K files (control } \\
\text { group) }(N=15)\end{array}$ & $\begin{array}{l}\text { Kedo-SH files } \\
\text { (experimental group) } \\
(N=15)\end{array}$ & $\begin{array}{l}\text { Kedo-SG Blue files } \\
\text { (experimental group) } \\
(N=15)\end{array}$ & Total $(N=45)$ & Overall $p$ value \\
\hline Age (years) & $6.67 \pm 0.900$ & $6.67 \pm 0.976$ & $6.33 \pm 0.900$ & $6.56 \pm 0.918$ & 0.528 \\
\hline \multicolumn{6}{|l|}{ Gender } \\
\hline Females \% & 53.3 & 60.0 & 46.7 & 53.3 & 0.765 \\
\hline Males \% & 46.7 & 40.0 & 53.3 & 46.7 & \\
\hline \multicolumn{6}{|l|}{ Tooth type distribution } \\
\hline Tooth 74\% & 26.7 & 13.3 & 26.7 & 22.2 & 0.893 \\
\hline Tooth $75 \%$ & 13.3 & 20.0 & 20.0 & 17.8 & \\
\hline Tooth $84 \%$ & 33.3 & 26.7 & 33.3 & 31.1 & \\
\hline Tooth $85 \%$ & 26.7 & 40.0 & 20.0 & 28.9 & \\
\hline \multicolumn{6}{|l|}{ Preoperative cause of pain } \\
\hline Pain on chewing \% & 53.3 & 20.0 & 53.3 & 42.2 & 0.297 \\
\hline Night pain \% & 20.0 & 33.3 & 13.3 & 22.2 & \\
\hline $\begin{array}{l}\text { Pain on intake of hot and cold } \\
\text { beverages } \%\end{array}$ & 26.7 & 46.7 & 33.3 & 35.6 & \\
\hline Total \% & 100 & 100 & 100 & 100 & \\
\hline
\end{tabular}

Chi-square test, $p<0.05$

Table 2: Depicting different quality of obturation in each group with overall $p$ value

\begin{tabular}{llllll}
\hline & \multicolumn{4}{c}{ Treatment (Group) } \\
\cline { 2 - 6 } Quality of obturation & $\begin{array}{l}\text { Hand-K files (control } \\
\text { group) }(N=15)\end{array}$ & $\begin{array}{l}\text { Kedo-SH files (experimental } \\
\text { group) }(N=15)\end{array}$ & $\begin{array}{l}\text { Kedo-SG Blue files } \\
\text { (experimental group) }(N=15)\end{array}$ & Total $(N=45)$ & Overall $p$ value \\
\hline Underfilling \% & 6.7 & 0.0 & 0.0 & 2.2 & $p<0.017(\text { Sig. })^{\text {a }}$ \\
Optimal filling \% & 20.0 & 46.7 & 80.0 & 48.9 \\
Overfilling \% & 73.3 & 53.3 & 20.0 & 48.9 \\
Total \% & 100 & 100 & 100 & 100 \\
\hline
\end{tabular}

Chi-square test, $p<0.05$

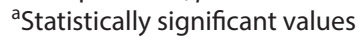

\section{Assessment of Postoperative Pain}

On completion of the procedure, postoperative pain assessment on the day of the procedure (day 1) was extracted over a telephonic conversation with participants using the WB-FPRS. Data pertaining to the postoperative pain was extracted similarly for a duration of 1 week.

\section{Statistical Analysis}

SPSS statistics software version 23.0 was used to perform the statistics. For descriptive data (i.e., age, gender, tooth type, preoperative cause of pain, pre- and postoperative pain assessment), descriptive statistics percentage analysis was done followed by one-way ANOVA and Pearson's Chi-square test to find the level of significance between the three groups. The mean pre- and postoperative pain levels during 1 week follow-up period between the three groups were analyzed using Kruskal-Wallis test followed by the Chi-square test to determine the level of significance among the groups on the different postoperative days. Intergroup comparison of postoperative pain assessment was done by Mann-Whitney $U$ test. Pearson's Chi-square test was used to compare the quality of obturation between the three groups and to find the significant group among the three intervention groups. Association of quality of obturation with postoperative pain assessment was also done by Chi-square test. A significance level of $p<0.05$ was set for the present study.

\section{Results}

\section{Baseline Demographic Profile of the Study Participants}

Forty-five children (24 females and 21 males) with the mean age of $6.56 \pm 0.918$ years participated in the study. Gender distribution of the recruited participants, tooth type, and the preoperative causes of pain in children between the three groups is tabulated in Table 1. There was an equal distribution of the participants with respect to demographic variables between the three groups [age ( $p=0.528)$, gender $(p=0.765)$, distribution of tooth type ( $p=$ $0.893)$, and the preoperative causes of pain $(p=0.297)]$, thereby preventing selection bias.

\section{Distribution of Quality of Obturation of the Study Participants}

A statistically significant and better quality of obturation was noted with Kedo-SG blue pediatric rotary files followed by Kedo hand files and hand K-files (Table 2). 
Table 3: Depicting percentage of pre- and postoperative pain assessment using Wong-Baker FACES pain rating scale in three different treatment groups (Hand K-files, Kedo-SH files, and Kedo-SG Blue files)

\begin{tabular}{|c|c|c|c|c|}
\hline $\begin{array}{l}\text { Pre-and postoperative pain } \\
\text { assessment }\end{array}$ & $\begin{array}{l}\text { Wong-Baker FACES pain } \\
\text { rating scale (pain score) }\end{array}$ & $\begin{array}{l}\text { Hand-K files (control } \\
\text { group) }(N=15) \%\end{array}$ & $\begin{array}{l}\text { Kedo-SH files (experimental } \\
\text { group) }(N=15) \%\end{array}$ & $\begin{array}{l}\text { Kedo-SG Blue files (experimental } \\
\text { group) }(N=15) \%\end{array}$ \\
\hline \multirow[t]{3}{*}{ Preoperative pain } & Mild pain & 20.0 & 33.3 & 40.0 \\
\hline & Moderate pain & 80.0 & 40.0 & 60.0 \\
\hline & Severe pain & 0.0 & 26.6 & 0.0 \\
\hline \multirow[t]{3}{*}{ Postoperative pain (day 1) } & Mild pain & 20.0 & 20.0 & 46.7 \\
\hline & Moderate pain & 66.7 & 53.4 & 53.4 \\
\hline & Severe pain & 13.3 & 26.7 & 0.0 \\
\hline \multirow[t]{3}{*}{ Postoperative pain (day 2) } & No pain & 6.7 & 6.7 & 13.3 \\
\hline & Mild pain & 40.0 & 53.3 & 73.3 \\
\hline & Moderate pain & 53.3 & 40.0 & 13.3 \\
\hline \multirow[t]{3}{*}{ Postoperative pain (day 3) } & No pain & 20.0 & 26.7 & 66.7 \\
\hline & Mild pain & 33.3 & 40.0 & 33.3 \\
\hline & Moderate pain & 46.6 & 33.3 & 0.0 \\
\hline \multirow[t]{3}{*}{ Postoperative pain (day 4) } & No pain & 33.3 & 60.0 & 86.7 \\
\hline & Mild pain & 53.3 & 26.7 & 13.3 \\
\hline & Moderate pain & 13.3 & 13.3 & 0.0 \\
\hline \multirow[t]{2}{*}{ Postoperative pain (day 5) } & No pain & 53.3 & 60.0 & 100.0 \\
\hline & Mild pain & 46.7 & 40.0 & 0.0 \\
\hline \multirow[t]{2}{*}{ Postoperative pain (day 6) } & No pain & 73.3 & 86.7 & 100.0 \\
\hline & Mild pain & 26.7 & 13.3 & 0.0 \\
\hline Postoperative pain (day 7) & No pain & 100.0 & 100.0 & 100.0 \\
\hline
\end{tabular}

\section{Pre- and Postoperative Pain Assessment during Follow-up in Intervention Groups}

The percentage analysis of pre- and postoperative pain evaluation done with the WB-FPRS in recruited children during 1 week follow-up period is tabulated in Table 3 . The postoperative pain was comparatively less in the group instrumented with Kedo-SG Blue rotary files when compared with the other two groups on day 3 and day 4 and also irrespective of the groups, a gradual decrease in the postoperative pain was noted on day 5 and day 6 while absolutely no pain was experienced in either of the three groups on day 7 (Fig. 2).

\section{Mean Pre- and Postoperative Pain during Follow-up in Intervention Groups}

Comparison of postoperative pain level during 1 week of the follow-up period was assessed using Kruskal-Wallis test and Pearson's Chi-square test. A statistically significant less postoperative pain was reported on instrumentation with Kedo-SG Blue files on day 1 followed by hand K-files and Kedo-SH group while on days 3,4 , and 5 , postoperative pain was reported to be comparatively less in the rotary Kedo-SG Blue group followed by Kedo-SH and hand K-files group (Table 4).

\section{Intergroup Comparison of Postoperative Pain Assessment (Days 1, 3, 4, and 5)}

Intergroup comparison of the three groups showed a statistically significant difference in the postoperative pain perception with Kedo-SG Blue files and conventional hand K-files. However, the pediatric and conventional hand files showed no significantly reduced pain. On comparing the pediatric hand and rotary file, a significant reduction in the postoperative pain was observed with

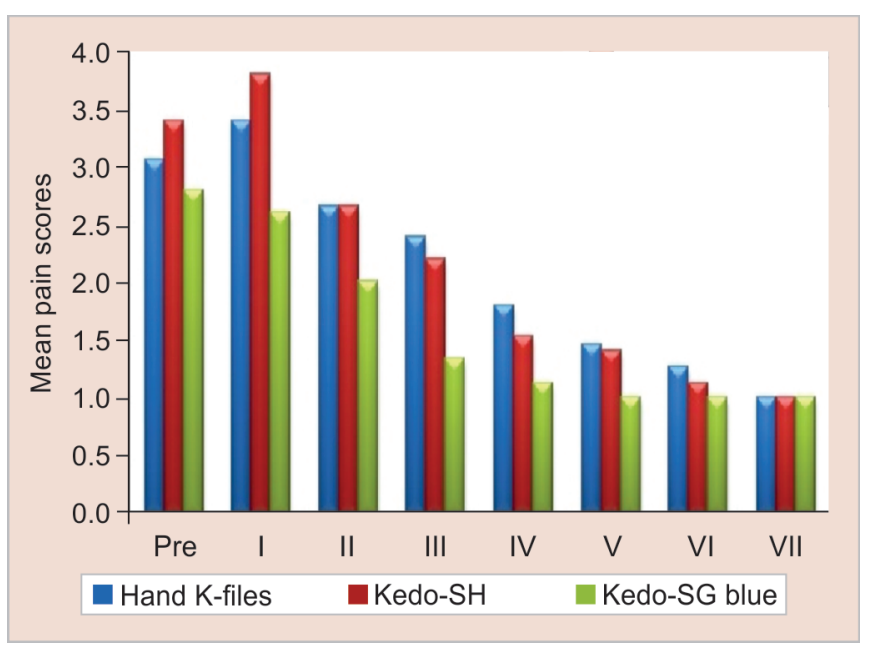

Fig. 2: Pre- and postoperative pain assessment

Kedo-SG blue rotary files on day 1; however, no significant difference was noted on the subsequent days (Table 5).

\section{Effect of the Quality of Obturation on Postoperative Pain Assessment}

The effect of the quality of obturation on the postoperative pain experience was studied (Table 6). Irrespective of the quality of obturation, children in all the groups experienced postoperative pain on days 1 and 2 . On days 3,4 , and 5 , it was observed that the majority of children experienced no pain with optimal filling, and only mild to moderate pain was experienced in children with overfilling which was statistically significant. However, on day 6 , it was noted that the majority of children with both optimal and overfilling experienced no pain which was also statistically significant (Table 6). 
Table 4: Depicting mean pre- and postoperative pain level during 1 week follow-up period in each group with overall $p$ value

\begin{tabular}{lcccc}
\hline & \multicolumn{4}{c}{ Treatment (Groups) } \\
\cline { 2 - 5 } $\begin{array}{l}\text { Pre- } \text { and postoperative pain } \\
\text { assessment }\end{array}$ & $\begin{array}{l}\text { Hand-K files (control } \\
\text { group) }(N=15)\end{array}$ & $\begin{array}{l}\text { Kedo-SH files (experimental } \\
\text { group) }(N=15)\end{array}$ & $\begin{array}{l}\text { Kedo-SG Blue files (experimental } \\
\text { group) }(N=15)\end{array}$ & Overall $p$ value \\
\hline Preoperative pain & $3.07 \pm 0.704$ & $3.40 \pm 1.454$ & $2.80 \pm 0.775$ & 0.538 \\
Postoperative pain (day 1) & $3.40 \pm 1.242$ & $3.80 \pm 1.424$ & $2.60 \pm 0.632$ & 0.025 (Sig.) \\
Postoperative pain (day 2) & $2.67 \pm 0.900$ & $2.67 \pm 1.047$ & $2.00 \pm 0.535$ & 0.070 \\
Postoperative pain (day 3) & $2.40 \pm 0.986$ & $2.20 \pm 1.014$ & $1.33 \pm 0.488$ & $0.004(\text { Sig.) })^{\mathrm{b}}$ \\
Postoperative pain (day 4) & $1.80 \pm 0.676$ & $1.53 \pm 0.743$ & $1.13 \pm 0.352$ & $0.014($ Sig.) \\
Postoperative pain (day 5) & $1.47 \pm 0.516$ & $1.40 \pm 0.507$ & $1.00 \pm 0.000$ & $0.011(\text { Sig.) })^{\mathrm{a}}$ \\
Postoperative pain (day 6) & $1.27 \pm 0.458$ & $1.13 \pm 0.352$ & $1.00 \pm 0.000$ & 0.105 \\
Postoperative pain (day 7) & $1.00 \pm 0.000$ & $1.00 \pm 0.000$ & $1.00 \pm 0.000$ & 1.000 \\
\hline
\end{tabular}

Kruskal-Wallis test, Chi-square test

aSignificant at $0.011<p \leq 0.050$

${ }^{\text {bHighly significant at } p \leq 0.01}$

Table 5: Depicting intergroup comparison of postoperative pain assessment (day 1, 3, 4, 5) with overall $p$ value

\begin{tabular}{|c|c|c|c|}
\hline Postoperative pain assessment & Treatment groups & Intergroup comparison & Overall $p$ value \\
\hline \multirow[t]{3}{*}{ Postoperative pain (day 1) } & Hand K-files & Kedo-SH files & 0.436 \\
\hline & Kedo-SH files & Kedo-SG Blue files & $0.015(\text { Sig. })^{a}$ \\
\hline & Kedo-SG Blue files & Hand K-files & 0.061 \\
\hline \multirow[t]{3}{*}{ Postoperative pain (day 3) } & Hand K-files & Kedo-SH files & 0.567 \\
\hline & Kedo-SH files & Kedo-SG Blue files & $0.016(\text { Sig. })^{\mathrm{a}}$ \\
\hline & Kedo-SG Blue files & Hand K-files & $0.003(\text { Sig. })^{\mathrm{b}}$ \\
\hline \multirow[t]{3}{*}{ Postoperative pain (day 4) } & Hand K-files & Kedo-SH files & 0.285 \\
\hline & Kedo-SH files & Kedo-SG Blue files & 0.187 \\
\hline & Kedo-SG Blue files & Hand K-files & $0.009(\text { Sig. })^{\mathrm{b}}$ \\
\hline \multirow[t]{3}{*}{ Postoperative pain (day 5) } & Hand K-files & Kedo-SH files & 0.775 \\
\hline & Kedo-SH files & Kedo-SG Blue files & 0.061 \\
\hline & Kedo-SG Blue files & Hand K-files & $0.029(\text { Sig. })^{a}$ \\
\hline
\end{tabular}

Mann-Whitney $U$ test

${ }^{\mathrm{a}}$ Significant at $0.011<p \leq 0.050$

bHighly significant at $p \leq 0.01$

\section{Discussion}

The concept of success or failure in endodontic treatment can often be relegated to obvious alleviation of preoperative signs and symptoms accompanied with minimal postoperative discomfort or pain. ${ }^{35}$ However, endodontic instrumentation is liable to cause a certain degree of post-instrumentation pain. Endodontic postoperative discomfort is defined as the occurrence of any degree of pain after an endodontic intervention. ${ }^{36}$ Postoperative pain has a multifactorial nature of causation such as patient's anxiety level, preoperative pain status, individual pain threshold, pulpal tissue remnants, mechanical and chemical irritation of the periapical tissues. ${ }^{37}$ Certain supportive evidence indicates that one of the most fundamental elements of postoperative endodontic pain is apical extrusion of the infected debris from the root apex during chemomechanical preparation resulting in an acute inflammatory response. $^{38}$

The field of dentistry has evolved tremendously and has witnessed a plethora of revolutionary changes in every aspect. One such revolutionary pathbreaking innovation in pediatric endodontics is the advent of pediatric hand and rotary files. Implementation of NiTi files for cleaning and shaping in primary teeth dates back to the use of Profile 0.04 taper rotary instruments by Barr et al. ${ }^{39}$ Since then the practice of rotary instrumentation in primary teeth has emerged enormously among the practitioners using NiTi files designed for permanent teeth. However, the use of exclusively designed pediatric rotary files in children came with the introduction of the Kedo-S (Kedo Dental Care Pvt. Ltd. India) rotary file system invented by Jeevanandan. ${ }^{40}$ Another major landmark to witness is the emergence of exclusive pediatric hand files (Kedo$\mathrm{SH}$ ) for effective debridement and preparation of the primary root canals. Only a few trials to date demonstrate the effect of manual $v s$ rotary instrumentation on the occurrence of postoperative pain in children using exclusive pediatric Kedo-S rotary file system ${ }^{29,30}$ while the first study on evaluation of postoperative pain following endodontic intervention in the pediatric population was conducted by Topçuoğlu et al. in 2017, which concluded that Revo-S rotary system caused less postoperative pain in primary teeth compared to conventional files. ${ }^{28}$ However, no available studies to date have found any effect of the quality of obturation on the postoperative pain following endodontic intervention in children.

A significant difference in the postoperative pain on follow-up days $1,3,4$, and 5 was recorded. However, on subsequent intergroup analysis, a significant difference was noted only between the pediatric rotary and hand files (Kedo-SG Blue and SH) on the 


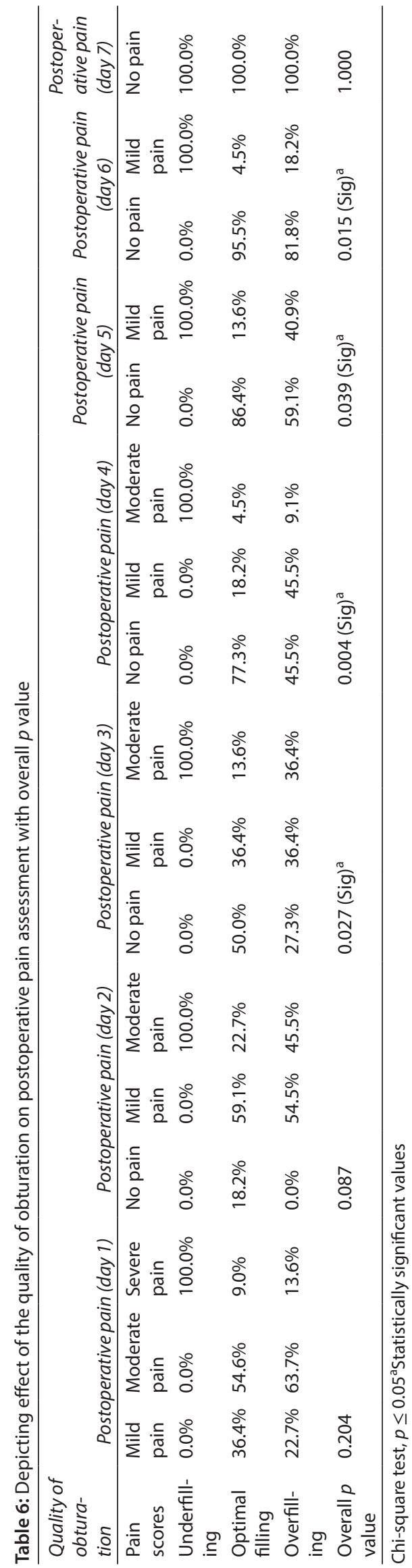

first day. Participants in the pediatric hand files (Kedo-SH) group experienced greater postoperative pain compared to the children in the rotary Kedo-SG Blue group. Some important contributing factors responsible for less postoperative pain level in the Kedo-SG Blue group could be firstly the implementation of a rotary system of instrumentation, resulting in minimal apical extrusion of debris which can be attributed to the file's variably variable taper, specifically designed tip diameter ${ }^{41,42}$ and use of only one file for root canal debridement. Secondly, the majority of children in the Kedo-SG Blue group had optimal filling, thereby relating to less postoperative pain on day 1 . While the majority of children treated under the Kedo-SH group had overfilling which could have contributed to greater postoperative pain. The extruded obturating material (i.e., Metapex) consists primarily of calcium hydroxide and iodoform combination. Apical extrusion of metapex results in the release of iodoform which is irritating to the periapical area and initiates inflammatory reaction causing pain. ${ }^{43}$

Similarly, on day 3, Kedo-SG blue group recorded less pain while no significant difference was noted between the conventional and pediatric hand files (Kedo-SH). The factors attributing to such a cause could be that stainless steel hand files result in greater extrusion of apical debris because of its push-and-pull filing technique ${ }^{24,25,42}$ and more number of files (i.e., No. 15-35) is needed for effective canal debridement resulting in greater flare-up reaction. The first two files of pediatric hand files (Kedo-SH) are also stainless steel in nature which could have also resulted in a certain degree of apical extrusion while the shaping files are NiTi in nature for efficient root canal preparation. On day 4 and day 5, again a significant difference in postoperative pain level was seen only between Kedo-SG Blue and hand K-files. Irrespective of the instrumentation material used, on day 6 only mild pain was observed in all of the three groups, and on day 7 no postoperative pain was observed in any of the groups. However, the results obtained in the present trial are not in consonance with the earlier trials ${ }^{28-30}$ conducted on postoperative pain using rotary and manual instrumentation in children which reported no postoperative pain experience after day 3 , while in the present study moderate to mild postoperative pain was still persistent till day 5 and majority of children experienced no postoperative pain only on day 6 .

The present study also outlined an association between the quality of obturation and postoperative pain level during the follow-up days which reported no significant impact of obturation quality on postoperative pain level on day 1 and day 2 . However, a significant association between the quality of obturation and postoperative pain level was observed on the remaining follow-up days except on day 7 where no postoperative pain was experienced in either of the groups. The greater percentage of children with optimal filling experienced either no postoperative pain $(50.0 \%)$ or mild postoperative pain (36.4\%) while the majority of the children with overfilling experienced mild to moderate postoperative pain (72.8\%) and children with underfilling experienced moderate postoperative pain on day 3 . Similar findings were also observed on day 4 with statistical significance.

On day 5 and day 6 , it was observed that children with optimal filling experienced more of no postoperative pain while children with overfilling and underfilling experienced mild postoperative pain and the results were statistically significant. While on day 7 irrespective of the quality of obturation, none of the children experienced postoperative pain.

No definitive assessment could be drawn regarding the impact of underfilling on postoperative pain level as there was only one 
underfilled finding reported which can be a potential limitation of the present study. Hence, it can be clearly and unequivocally stated that quality of obturation also has a major role to play in either intensifying or alleviating the postoperative pain level and optimally filled teeth eventually experience no pain or minimal degree of postoperative discomfort. However, further trials are needed to delineate clearly the impact of quality of obturation on postoperative pain level.

\section{Conclusion}

- Decreased postoperative pain was noted with pediatric rotary files (Kedo-SG Blue).

- Optimal filling results in less postoperative pain.

- Further investigations overcoming the limitations of the present study are needed to support the results of the present study.

\section{Importance of this Paper to Pediatric Dentists}

- It enlightens that precise pain assessment and its successful management is an integral component of pediatric dental practice.

- It enlightens the importance of different instrumentation techniques in the causation of postoperative pain in children.

- It enlightens the quintessential role of quality of obturation in anticipating the degree of postoperative pain in children.

\section{Authors' Contribution}

Ganesh Jeevanandan devised the project. Pragyna Priyadarshini gave the main conceptual ideas, conducted the complete study, data analysis, and manuscript writing. Pragyna Priyadarshini, Lavanya Govindaraju, Ganesh Jeevanandan, EMG Subramanian revised the manuscript, analysis, and drafted the final manuscript. All authors have made substantial contributions to the present study and manuscript and all have reviewed the final paper before its submission.

\section{FiELD OF WORK}

The present study was conducted in the Department of Paediatric and Preventive Dentistry, Saveetha Dental College and Hospitals, Saveetha Institute of Medical and Technical Sciences, Chennai, Tamil Nadu, India.

\section{ACKnOWLedgments}

The authors would like to thank all the participating parents and children.

\section{References}

1. Garcia-Godoy F. Evaluation of an iodoform paste in root canal therapy for infected primary teeth. J Dent Child 1987;54(1):30-34.

2. Mohamed HAA. Pulpectomy procedures in primary molar teeth. Eur J Gen Dent 2014;3(1):3-10. DOI: 10.4103/2278-9626.126201.

3. Brothwell DJ. Guidelines on the use of space maintainers following premature loss of primary teeth. J Can Dent Assoc 1997;63(10):753766.

4. Rahbaran S, Gilthorpe MS, Harrison SV, et al. Comparison of clinical outcome of periapical surgery in endodontic and oral surgery units of a teaching dental hospital: a retrospective study. Oral Surg Oral
Med Oral Pathol Oral Radiol Endod 2001;91(6):700-709. DOI: 10.1067/ moe.2001.114828.

5. Eleazer PD, Eleazer KR. Flare-up rate in pulpally necrotic molars in onevisit versus two-visit endodontic treatment. J Endod 1998;24(9):614616. DOI: 10.1016/S0099-2399(98)80122-2.

6. Azar MR, Safi L, Nikaein A. Comparison of the cleaning capacity of Mtwo and Pro Taper rotary systems and manual instruments in primary teeth. Dent Res J (Isfahan) 2012;9(2):14651. DOI: 10.4103/17353327.95227.

7. Fuks $A B$. Pulp therapy for the primary dentition. In: Pinkham JR, Casamassimo PS, Mc Tigue DJ, et al., ed. Pediatric dentistry: infancy through adolescence. 4th ed., Philadelphia: WB Saunders Co; 2005. p. 390.

8. Bashetty K, Hegde J. Comparison of $2 \%$ chlorhexidine and $5.25 \%$ sodium hypochlorite irrigating solutions on postoperative pain: a randomized clinical trial. Indian J Dent Res 2010;21(4):523-527. DOI: 10.4103/0970-9290.74225.

9. Elmubarak $\mathrm{AHH}$, Abu-Bakr NH, Ibrahim $\mathrm{YE}$, et al. Postoperative pain in multiple-visit and single-visit root canal treatment. J Endod 2010;36(1):36-39. DOI: 10.1016/j.joen.2009.09.003.

10. Nekoofar MH, Sheykhrezae MS, Meraji N, et al. Comparison of the effect of root canal preparation by using Waveone and Protaper on postoperative pain: a randomized clinical trial. J Endod 2015;41(5):575-578. DOI: 10.1016/j.joen.2014.12.026.

11. Pasqualini D, Mollo L, Scotti N, et al. Postoperative pain after manual and mechanical glide path: a randomized clinical trial. J Endod 2012;38(1):32-36. DOI: 10.1016/j.joen.2011.09.017.

12. Alves VO. Endodontic flare-ups: a prospective study. Oral Surg Oral Med Oral Pathol Oral Radiol Endod 2010;110(5):68-72. DOI: 10.1016/j. tripleo.2010.05.014.

13. Masoud P, Jalali S, Haghdoost AA, et al. Comparison of the effect of various irrigants on apically extruded debris after root canal preparation. J Endod 2012;38(1):21-27. DOI: 10.1111/j.17474477.2010.00268.x.

14. Pozos-Guillen A, Martinez-Rider R, Aguirre-Banuelos P, et al. Preemptive analgesic effect of tramadol after mandibular third molar extraction: a pilot study. J Oral Maxillofac Surg 2007;65(7):1315-1320. DOI: 10.1016/j.joms.2006.10.079.

15. Shafie $L$, Barghi $H$, Parirokh $M$, et al. Postoperative pain following pulpotomy of primary molars with two biomaterials: a randomized split mouth clinical trial. Iran Endod J 2017;12(1):10-14. DOI: 10.22037/ iej.2017.02.

16. Subbiya A, Cherkas PS, Vivekanandhan P, et al. Effect of three different rotary instrumentation systems on postinstrumentation pain: a randomized clinical trial. J Conserv Dent 2017;20(6):467-473. DOI: 10.4103/JCD.JCD_350_16.

17. Ng YL, Glennon JP, Setchell DJ, et al. Prevalence of and factors affecting post-obturation pain in patients undergoing root canal treatment. Int Endod J 2004;37(6):381-391. DOI: 10.1111/j.13652591.2004.00820.x.

18. Chavez de Paz Villanueva LE. Fusobacterium nucleatum in endodontic flare-up. Oral Surg Oral Med Oral Pathol Oral Radiol Endod 2002;93(2):179-183. DOI: 10.1067/moe.2002.120803.

19. Glennon JP, Ng YL, Setchell DJ, et al. Prevalence of and factors affecting post operation pain in patient undergoing two visit root canal treatment. Int Endod J 2004;37(1):29-37. DOI: 10.1111/j.13652591.2004.00748.x.

20. Alonso-Ezpeleta LO, Gasco-Garcia C, Castellanos-Cosano L, et al. Postoperative pain after one-visit root-canal treatment on teeth with vital pulps: comparison of three different obturation techniques. Med Oral Patol Oral Cir Bucal 2012;17(4):e721-e727. DOI: 10.4317/ medoral.17898.

21. Goreva LA, Petrikas AZH. Postobturation pain associated with endodontic treatment. Stomatologiia (Mosk) 2004;83(2):14-16.

22. Makeeva IM, Turkina AIU. Effects of the method of mechanical root canal treatment on emergence of pain after endodontic management. Stomatologiia (Mosk) 2005;84(5):21-23. 
23. Genet JM, Hart AA, Wesselink PR, et al. Preoperative and operative factors associated with pain after the first endodontic visit. Int Endod J 1987;20(2):53-64. DOI: 10.1111/j.1365-2591.1987.tb00590.x.

24. Shahi S, Asghari V, Rahimi S, et al. Postoperative pain after endodontic treatment of asymptomatic teeth using rotary instruments: a randomized clinical trial. Iran Endod J 2016;11(1):38-43. DOI: 10.7508/ iej.2016.01.008.

25. Vaudt J, Bitter K, Neumann K, et al. Ex vivo study on root canal instrumentation of two rotary nickel-titanium systems in comparison to stainless steel hand instruments. Int Endod J 2009;42(1):22-33. DOI: 10.1111/j.1365-2591.2008.01489.x.

26. Talebzadeh B, Nezafati S, Rahimi S, et al. Comparison of manual and rotary instrumentation on postoperative pain in teeth with asymptomatic irreversible pulpitis: a randomized clinical trial. Iran Endod J 2016;11(4):273-279. DOI: 10.22037/iej.2016.4.

27. Gupta S, Dhir S, Thakur BD, et al. Comparison of the Incidence of post-operative pain and time taken for instrumentation using manual and rotary techniques and obturation in single-visit endodontics, in young permanent teeth - an in vivo study. Int J Oral Care Res 2018;6(2):S15-S18.

28. Topçuoğlu G, Topçuoğlu HS, Delikan E, et al. Postoperative pain after root canal preparation with hand and rotary files in primary molar teeth. Pediatr Dent 2017;39(3):192-196.

29. Nair M, Jeevanandan $G$, Vignesh $R$, et al. Comparative evaluation of post-operative pain after pulpectomy with $\mathrm{K}$-files, Kedo-S files and MTwo files in deciduous molars - a randomized clinical trial. Braz Dent Sci 2018;21(4):411-417. DOI: 10.14295/bds.2018.v21i4.1617.

30. Panchal V, Jeevanandan G, Subramanian EM. Comparison of postoperative pain after root canal instrumentation with hand K-files, $\mathrm{H}$-files and rotary Kedo-S files in primary teeth: a randomized clinical trial. Eur Arch Paediatr Dent 2019;20(5):467-472. DOI: 10.1007/s40368019-00429-5.

31. Altman DG, Schulz KF, Moher D, et al. The revised CONSORT statement for reporting randomized trials: explanation and elaboration. Ann Intern Med 2001;134(8):663-694. DOI: 10.7326/0003-4819-134-8200104170-00012.

32. Parirokh M, Yosefi MH, Nakhaee N, et al. Effect of bupivacaine on postoperative pain for inferior alveolar nerve block anesthesia after single-visit root canal treatment in teeth with irreversible pulpitis. J Endod 2012;38(8):1035-1039. DOI: 10.1016/j.joen.2012. 04.012.

33. Garra G, Singer AJ, Taira BR, et al. Validation of the Wong-Baker FACES pain rating scale in pediatric emergency department patients. Acad Emerg Med 2010;17(1):51-54. DOI: 10.1111/j.1553-2712.2009. 00620.x.

34. Coll JA, Sadrian R. Predicting pulpectomy success and its relationship to exfoliation and succedaneous dentition. Pediatr Dent 1996;18(1):57-63.

35. Gutmann JL, Lovdahl PE. Problems in the assessment of success and failure, quality assurance, and their integration into endodontic treatment planning. In: Gutmann JL, Dumsha TC, Lovdahl PE, et al., ed. Problem Solving In Endodontics. 3rd ed., St. Louis, MO: Elsevier; 1997. pp. 1-22.

36. Sathorn C, Parashos $P$, Messer $H$. The prevalence of postoperative pain and flare-up in single and multiple visit endodontic treatment: a systematic review. Int Endod J 2008;41(2):91-99. DOI: 10.1111/j.13652591.2007.01316.x.

37. Ince B, Ercan E, Dalli M, et al. Incidence of postoperative pain after single-and multi-visit endodontic treatment in teeth with vital and non-vital pulp. Eur J Dent Oct 2009;3(4):273-279. DOI: 10.1055/s-00391697444.

38. Seltzer S, Naidorf IJ. Flare-ups in endodontics: I. Etiologicalfactors. J Endod 1985;30(7):476-481. DOI: 10.1097/ 00004770-200407000-00005discussion 5, 2004; 30(7): 476-481.

39. Barr ES, Kleier DJ, Barr NV. Use of nickel-titanium rotary files for root canal preparation in primary teeth. Pediatr Dent 2000;22(1):77-78.

40. Jeevanandan $G$. Kedo $S$ paediatric rotary files for root canal preparation in primary teeth - case report. J Clin Diagn Res 2017;11(3):ZR03-ZR05. DOI: 10.7860/JCDR/2017/25856.9508.

41. Mangalam S, Rao CV, Lakshminarayanan L. Evaluation of apically extruded debris and irrigant using three instrumentation techniques. Endodontology 2002;14:19-23.

42. Reddy S, Hicks L. Apical extrusion of debris using two hand and two rotary instrumentation techniques. J Endod 1998;24(3):180-183. DOI: 10.1016/S0099-2399(98)80179-9.

43. Erasquin J, Muruzabal M. Root canal fillings with zinc oxide eugenol in the rat molar. Oral Surg Oral Med Oral Pathol 1967;24(4):547-558. DOI: 10.1016/0030-4220(67)90436-7. 